\title{
Nature of Alkali Ion Conduction and Reversible Na-ion Storage in Hybrid Formate Framework Materials
}

\author{
A. Polek, ${ }^{a}$ C. Cazorla ${ }^{b}$ and D. Kundu*c \\ ${ }^{a}$ Dept. of Materials, ETH Zurich, Switzerland. \\ ${ }^{b}$ Departament de Fisica, Universitat Politecnica de Catalunya, Campus Nord B4-B5, E- \\ 08034 Barcelona, Spain \\ ${ }^{c}$ School of Chemical Engineering, UNSW Sydney, Kensington 2052, Australia
}

\begin{abstract}
The cost advantage of Na-ion batteries has spurred intensive research effort in the last ten years to develop reversible $\mathrm{Na}^{+}$storage materials. While classic host materials - analogous to the Liion system - are potentially straightforward targets, sluggish $\mathrm{Na}^{+}$diffusion in many inorganic structures limit options. In this regard, open framework inorganic-organic hybrids like metalorganic framework materials are considered as viable alternatives. Herein we introduce heterometallic formate frameworks as potential candidates for reversible $\mathrm{Na}^{+}$storage. In a first, we present a microwave solvothermal strategy for rapid synthesis of phase pure microcrystalline $\mathrm{Na}_{2} \mathrm{Co}\left(\mathrm{HCO}_{2}\right)_{4}$ and $\mathrm{AB}\left(\mathrm{HCO}_{2}\right)_{3}(\mathrm{~A}: \mathrm{Li} / \mathrm{Na} ; \mathrm{B}: \mathrm{Co} / \mathrm{Mn})$. By combining indepth impedance analysis with ab-initio molecular dynamics simulation, we reveal that the $\mathrm{Li}^{+} / \mathrm{Na}^{+}$conduction - which follows a 'pinball' mechanism - in these materials is extrinsic defect dominated. Calculation suggests that a librational motion of the formate anions facilitates the diffusion of $\mathrm{Na}^{+}$compared to $\mathrm{Li}^{+}$, explaining the origin of anomalously higher ionic conductivity for the $\mathrm{Na}$ analogue compared to the Li one. Preliminary electrochemical investigation reveals reversible $\mathrm{Na}^{+}$storage in $\mathrm{Na}_{2} \mathrm{Co}\left(\mathrm{HCO}_{2}\right)_{4}$ and $\mathrm{NaMn}\left(\mathrm{HCO}_{2}\right)_{3}$ at an average voltage of 2.5-3 V.
\end{abstract}

\section{KEYWORDS}

Inorganic-organic hybrids, formate framework materials, Na-ion conduction, reversible $\mathrm{Na}^{+}$ storage, microwave synthesis 


\section{INTRODUCTION}

Once forsaken for higher energy Li-ion batteries (LIBs), research on Na-ion batteries (NIBs) have attracted tremendous attention in the last decade owing to sodium's high abundance and inexpensiveness, which make NIBs attractive for large-scale and renewable energy storage. ${ }^{1-3}$ In the search for $\mathrm{Na}^{+}$host materials, many $\mathrm{Na}$-analogues of classic inorganic Li-hosts have been developed, but the larger size of $\mathrm{Na}^{+}(1: 06 \AA)$ compared to $\mathrm{Li}^{+}(0: 76 \AA)$ results in different - most often inferior - electrochemical charge storage behavior. ${ }^{3,4}$ Thus, the development of novel materials, specifically based on open structures, is essential. To this end, inorganicorganic hybrids - where metal centers are three-dimensionally (3D) templated by organic ligands - offer numerous possibilities. ${ }^{5,6}$ They combine the advantages of both inorganic and organic materials. Organic compounds are presumably more sustainable and offer a molecular toolbox of diverse redox functions, but their solubility in typical organic electrolytes is detrimental for long-term cycling. ${ }^{7}$ Organic-inorganic hybrids are however intrinsically insoluble in organic solvents like the inorganic materials. ${ }^{8-11}$ These coordination polymers are closely related to metal-organic framework (MOFs) compounds which have been the subject of considerable interests for diverse energy storage related applications. ${ }^{12,13}$ A vast majority of them are based on carboxylate group containing organic ligands, which coordinate to the metal ions. ${ }^{14-17}$ While several MOFs have been studied for LIB cathode ${ }^{8,18,19}$ and anode applications ${ }^{14,20,21}$ the number remains low, and besides hexacyanoferrate materials that are generally classified as purely inorganic systems, report on MOFs for $\mathrm{Na}^{+}$storage is rare. ${ }^{22}$

Heterometallic formates, such as $\mathrm{A}_{2} \mathrm{~B}\left(\mathrm{HCO}_{2}\right)_{4}$ and $\mathrm{AB}\left(\mathrm{HCO}_{2}\right)_{3}(\mathrm{~A}: \mathrm{Li} / \mathrm{Na} ; \mathrm{B}: \mathrm{Mn} / \mathrm{Co})$, belong to organic-inorganic hybrid class of materials. Strictly speaking, these materials cannot be termed as MOFs as they contain M-O-M (M: metal) units or single oxygen bridging two metal centers. Based on an autoclave-assisted solvothermal method, the synthesis of single crystals of $\mathrm{Na}_{2} \mathrm{Co}\left(\mathrm{HCO}_{2}\right)_{4},{ }^{23} \mathrm{NaMn}\left(\mathrm{HCO}_{2}\right)_{3},{ }^{24} \mathrm{LiCo}\left(\mathrm{HCO}_{2}\right)_{3},{ }^{25}$ and $\mathrm{LiMn}\left(\mathrm{HCO}_{2}\right)_{3}{ }^{25}$ and their crystal 
structures were reported earlier. The interests in these materials were mainly owing to their magnetic behavior, facilitated by the rather short formate anion $\mathrm{HCOO}^{-}$which allows magnetic coupling between the transition metals. From redox chemistry perspective, all four compounds may undergo $\mathrm{Co} / \mathrm{Mn}$ oxidation/reduction between $2+$ and $3+$ oxidation state leading to reversible $\mathrm{Na}^{+} / \mathrm{Li}^{+}$storage. Whereas structurally considering, the $\mathrm{Na}$ ions in between the $\mathrm{Co}-$ formate layers in monoclinic $\mathrm{Na}_{2} \mathrm{Co}\left(\mathrm{HCO}_{2}\right)_{4}($ Figure 1a) and $\mathrm{Na} / \mathrm{Li}$ ions residing in the tunnels in cubic $\mathrm{AM}\left(\mathrm{HCO}_{2}\right)_{3}$ (Figure 1b; $\mathrm{A}: \mathrm{Na} / \mathrm{Li}$ and $\left.\mathrm{M}: \mathrm{Co} / \mathrm{Mn}\right)$ are likely to be mobile. Additionally, the soft formate anionic framework is expected to bind the alkali ions weakly, which can potentially aid the alkali ion mobility in these structures.

As we showcase here, the microcrystalline heterometallic formates can be synthesized by a rapid microwave solvothermal technique that has not been demonstrated earlier for hybrid formate materials. The materials display a "pinball" ionic conduction mechanism with anomalously higher ionic conductivity for the $\mathrm{Na}$ analogue compared to the $\mathrm{Li}$ one - as revealed by impedance spectroscopy analysis and molecular dynamics simulation. Preliminary electrochemical cycling confirms reversible $\mathrm{Na}^{+}$storage behavior.

\section{RESULTS AND DISCUSSION}

Synthesis and characterization. Phase pure micro or nanocrystalline powder material is essential for physicochemical and electrochemical analysis relevant to battery material application. Solvothermal reactions that have been applied so far to synthesize the target formate compounds typically result in large crystal, and often accompany impurities. Therefore, a microwave heat treatment mediated solvothermal synthesis route was developed that dramatically brought down the reaction time from $48-72 \mathrm{~h}$ - required for regular solvothermal - to only 30 minutes (see experimental details). This is the first time a rapid microwave solvothermal technique is demonstrated for the synthesis of heterometallic formate frameworks. The phase purity of the as-synthesized $\mathrm{Na}_{2} \mathrm{Co}\left(\mathrm{HCO}_{2}\right)_{4}, \mathrm{NaMn}\left(\mathrm{HCO}_{2}\right)_{3}$, 
$\mathrm{LiCo}\left(\mathrm{HCO}_{2}\right)_{3}$, and $\mathrm{LiMn}\left(\mathrm{HCO}_{2}\right)_{3}$ was confirmed from powder X-ray diffraction (XRD) patterns, shown in Figure 1c-f. No impurity peaks were observed, and all patterns matched well with the corresponding reference pattern generated from the single crystal data reported earlier. Efforts to synthesize $\mathrm{NaCo}\left(\mathrm{HCO}_{2}\right)_{3}$ led to the formation of an unidentified white color impurity along with the pink target material, which was confirmed by XRD (Figure S1). The chemical identity of the compounds - consisting of the formate anionic framework was further validated by infrared spectroscopic analysis (Figure S2). All the formates have almost identical spectra - which are primarily dominated by fingerprints of formate and confirm the absence of any solvent impurity.
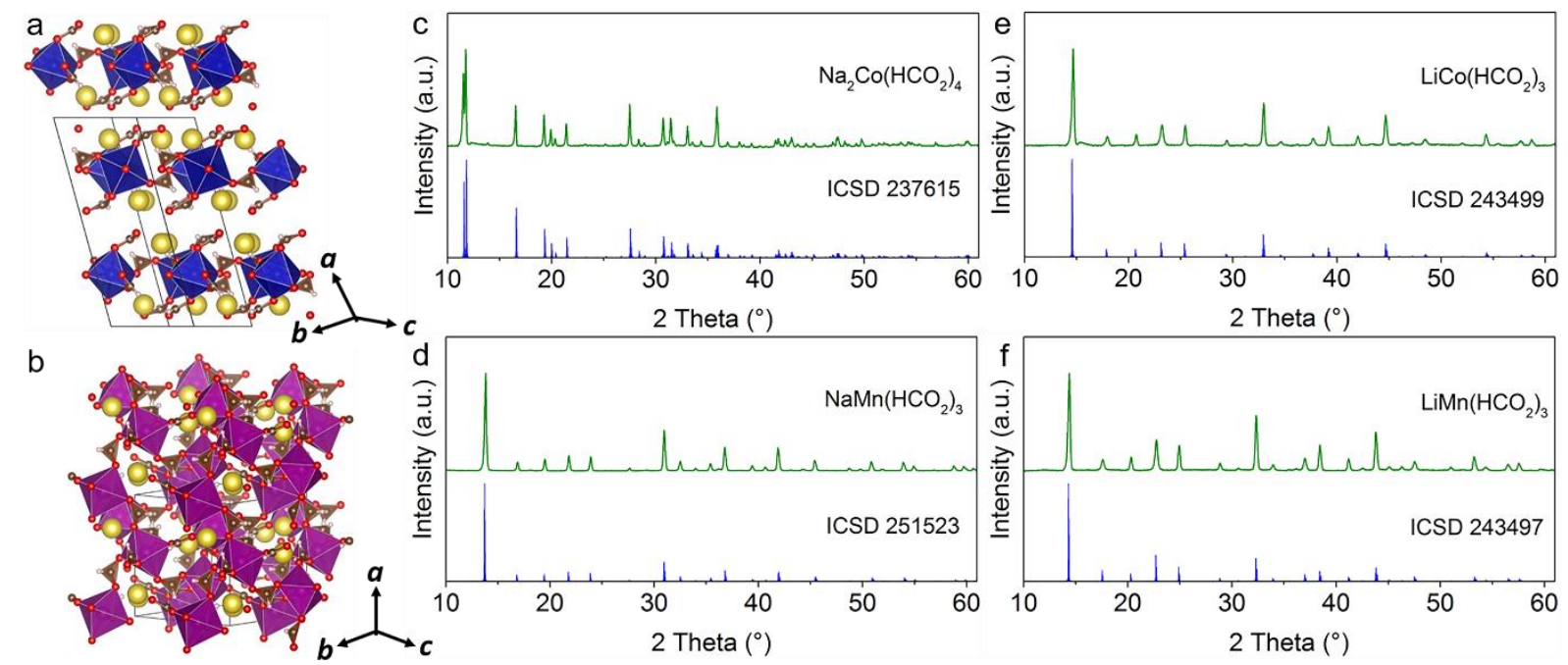

Figure 1. Powder X-ray diffraction pattern of the as-synthesized polycrystalline (a) $\mathrm{Na}_{2} \mathrm{Co}\left(\mathrm{HCO}_{2}\right)_{4}$, (b) $\mathrm{NaMn}\left(\mathrm{HCO}_{2}\right)_{3}$, (c) $\mathrm{LiCo}\left(\mathrm{HCO}_{2}\right)_{3}$, and (d) $\mathrm{LiMn}\left(\mathrm{HCO}_{2}\right)_{3}$. The corresponding reference patterns are shown in blue.

Thermal analysis data as presented in Figure S3 (Table S1; under nitrogen atmosphere) reveal that the as-synthesized materials are stable up to $200-250^{\circ} \mathrm{C}$ and thus possess adequate oxidative stability for battery electrode application. The formates are expected to decompose to metal oxides accompanying the release of $\mathrm{CO}, \mathrm{H}_{2} \mathrm{O}$ and possibly $\mathrm{H}_{2}$. Elemental microanalysis was performed to determine the carbon content in the form of the formate anion. Based on carbon analysis data presented in Table S2, it can be said that the carbon content of 
the pure compounds agrees well with their nominal composition. Morphology of the materials as investigated by scanning electron microscopy (SEM) study is shown in Figure 2. As evident from Figure 2a, $\mathrm{Na}_{2} \mathrm{Co}\left(\mathrm{HCO}_{2}\right)_{4}$ consists of rod-shaped particles that are between 30 and 100 $\mu \mathrm{m}$ in length and 5-7 $\mu \mathrm{m}$ in diameter. The $\mathrm{Na}$ to Co ratio was confirmed to be 2:1 by energy dispersive X-ray analysis (see EDX data in Figure S4). The cubic structure $\mathrm{AM}\left(\mathrm{HCO}_{2}\right)_{3}(\mathrm{~A}$ : $\mathrm{Li} / \mathrm{Na}$ and $\mathrm{M}: \mathrm{Co} / \mathrm{Mn}$ ) materials are comparable in dimension with particle size ranging from $200 \mathrm{~nm}$ to $2 \mu \mathrm{m}$ and display somewhat similar irregular polyhedral morphology. The polyhedral shapes are discernable for $\mathrm{LiCo}\left(\mathrm{HCO}_{2}\right)_{3}$ (Figure 2c) but deformed for $\mathrm{NaMn}\left(\mathrm{HCO}_{2}\right)_{3}$ (Figure 2b) and $\mathrm{LiMn}\left(\mathrm{HCO}_{2}\right)_{3}$ (Figure 2d). EDX analysis of the $\mathrm{Na}$ to $\mathrm{Mn}$ ratio on $\mathrm{NaMn}\left(\mathrm{HCO}_{2}\right)_{3}$ particles confirmed the nominal composition.
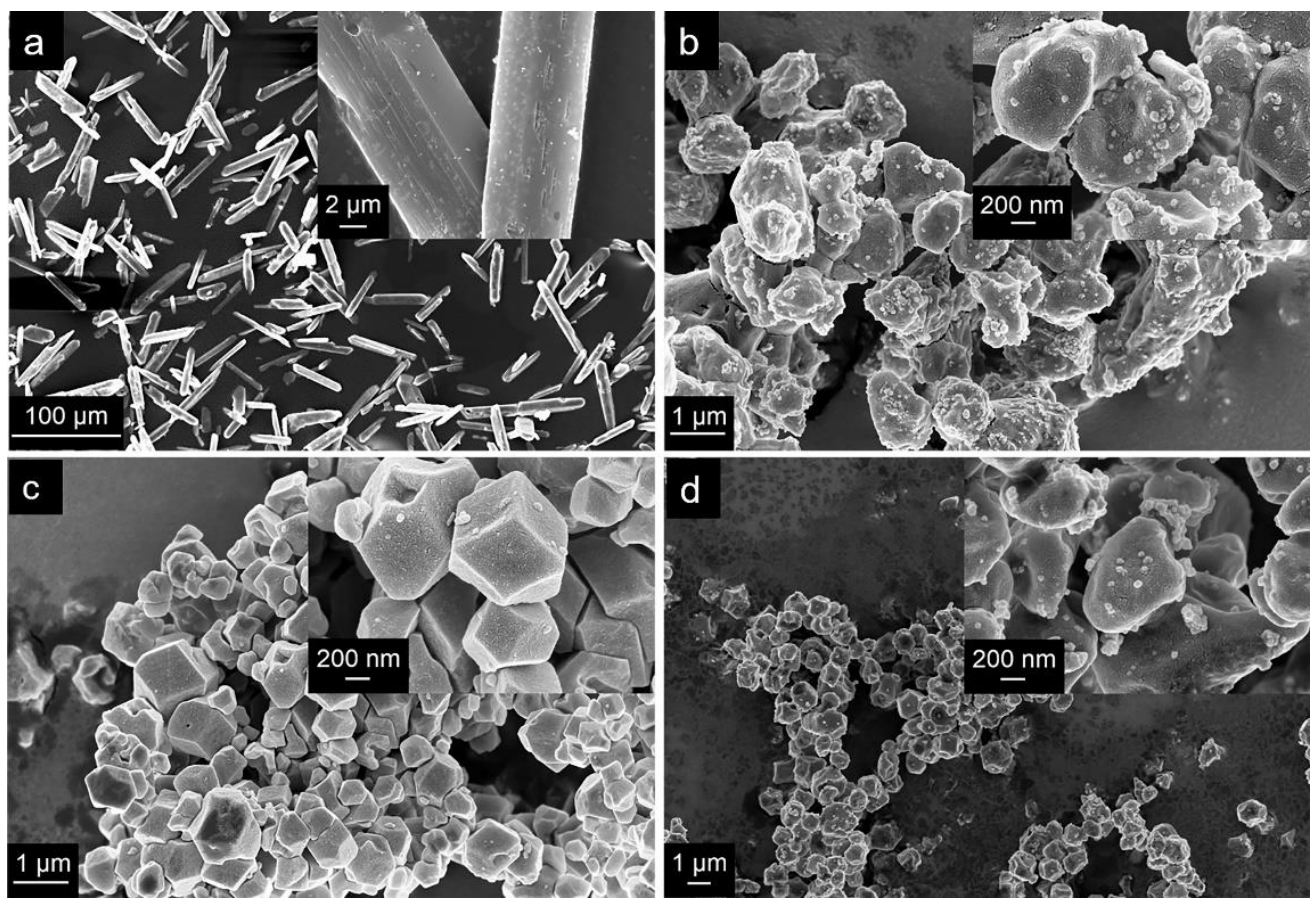

Figure 2. Typical SEM images showing the morphology of the as-synthesized (a) $\mathrm{Na}_{2} \mathrm{Co}\left(\mathrm{HCO}_{2}\right)_{4}$, (b) $\mathrm{NaMn}\left(\mathrm{HCO}_{2}\right)_{3}$, (c) $\mathrm{LiCo}\left(\mathrm{HCO}_{2}\right)_{3}$ and (d) and $\mathrm{LiMn}\left(\mathrm{HCO}_{2}\right)_{3}$.

$\mathrm{Li}^{+} / \mathrm{Na}^{+}$conductivity study. Mobility of the $\mathrm{Li} / \mathrm{Na}$ ions in the formate frameworks, which is necessary for their electrochemical cycling, was probed by electrochemical impedance spectroscopy. Figure 3a-d show the Nyquist impedance plots at different temperatures and the 
corresponding plots depicting the variation of the bulk ionic conductivity (natural logarithm) as a function of temperature are presented in Figure 3e-h. The bulk ionic conductivities were extracted by fitting the impedance data with an equivalent circuit (Figure S5), and the activation energies for the Li/Na-ion mobility were revealed by Arrhenius type fitting shown in Figure 3e-h. The parameters obtained from fitting are presented in Table S3. From the Arrhenius plot of $\mathrm{Na}_{2} \mathrm{Co}\left(\mathrm{HCO}_{2}\right)_{4}$ in Figure 3e, it is apparent that the nature of Na-ion diffusion changes with increasing temperature. Until $90^{\circ} \mathrm{C}$ the activation energy is $0.28 \mathrm{eV}$ atom ${ }^{-1}$, which is relatively low. In the window up to $130^{\circ} \mathrm{C}$ the barrier is a high $0.62 \mathrm{eV}^{\text {atom }}{ }^{-1}$ but decreases to a very low $0.07 \mathrm{eV}^{\text {atom }}{ }^{-1}$ above $130^{\circ} \mathrm{C}$. Such jumps in the activation barrier most likely stem from a change in the ionic conduction mechanism from an extrinsic type at lower temperatures to an intrinsic one at higher temperatures when intrinsic defects such as vacancies can be formed, which dominate the ionic mobility. Usually intrinsic defects are formed at much higher temperatures than observed here, but as the thermal stability of $\mathrm{Na}_{2} \mathrm{Co}\left(\mathrm{HCO}_{2}\right)_{4}$ is much lower, defects are not unlikely at low temperatures. $\mathrm{NaMn}\left(\mathrm{HCO}_{2}\right)_{3}$ displays similar behavior (Figure 3f) where the activation energy of Na-ion migration increases from $0.07 \mathrm{eV}^{\text {atom }}{ }^{-1}$ to $0.70 \mathrm{eV}$ atom ${ }^{-1}$ at around $110^{\circ} \mathrm{C}$. The $\mathrm{Li}$ compounds $\mathrm{LiCo}\left(\mathrm{HCO}_{2}\right)_{3}$ and $\mathrm{LiMn}\left(\mathrm{HCO}_{2}\right)_{3}$ show activation barriers of $0.20 \mathrm{eV}$ atom $^{-1}$ and $0.34 \mathrm{eV}$ atom ${ }^{-1}$, respectively, with only one Arrhenius slope and thus no change in ionic conduction mechanism with increasing temperature. Room temperature bulk ionic conductivity of each compound was extrapolated from the linear fit of the corresponding Arrhenius plot (Table S4). While $\mathrm{Na}_{2} \mathrm{Co}\left(\mathrm{HCO}_{2}\right)_{4}$ and $\mathrm{LiCo}\left(\mathrm{HCO}_{2}\right)_{3}$ have similar ionic conductivity $\left(\sim 10^{-6} \mathrm{~S} \mathrm{~cm}^{-1}\right), \mathrm{NaMn}\left(\mathrm{HCO}_{2}\right)_{3}$ displays a rather high ionic conductivity of $\sim 10^{-4} \mathrm{~S} \mathrm{~cm}^{-1}$ that is four orders of magnitude higher than that of $\operatorname{LiMn}\left(\mathrm{HCO}_{2}\right)_{3}$ despite $\mathrm{Na}^{+}$being larger than $\mathrm{Li}^{+}$and both compounds having identical structure. 

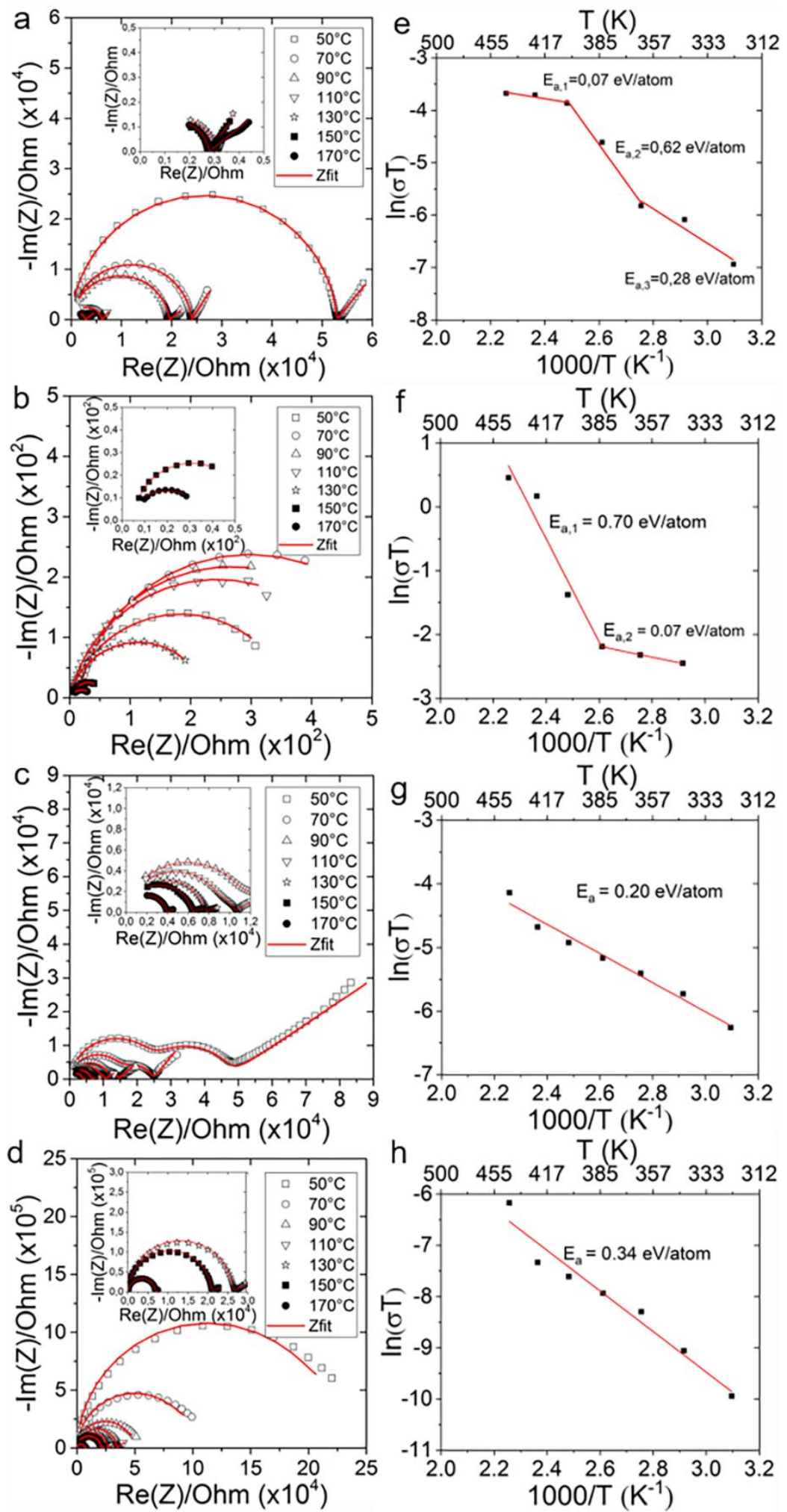

Figure 3. AC impedance data (left column) at different temperatures and Arrhenius type fitting of the bulk ionic conductivity value (right column) for (a, e) $\mathrm{Na}_{2} \mathrm{Co}\left(\mathrm{HCO}_{2}\right)_{4}$, (b, f) $\mathrm{NaMn}\left(\mathrm{HCO}_{2}\right)_{3},(\mathrm{c}, \mathrm{g}) \mathrm{LiCo}\left(\mathrm{HCO}_{2}\right)_{3}$ and $(\mathrm{d}, \mathrm{h}) \mathrm{LiMn}\left(\mathrm{HCO}_{2}\right)_{3}$. The fitted lines in solid red. 
To further understand and characterize the ionic conductivity of heterometallic formate frameworks, we performed first-principles simulations based on density functional theory (DFT). ${ }^{26}$ Ionic diffusion involves highly anharmonic and $T$-dependent processes, ${ }^{27}$ thus we employed ab initio molecular dynamics (AIMD) simulations to accurately describe them (Supporting Information). Ionic transport was characterized by estimating the mean-squared displacement, MSD, and diffusion coefficient, $D$, of all the atomic species in $\operatorname{LiMn}\left(\mathrm{HCO}_{2}\right)_{3}$ and $\mathrm{NaMn}\left(\mathrm{HCO}_{2}\right)_{3}$ (Supporting Information).

By considering perfectly ordered and stoichiometric systems, we estimated small lithium and sodium diffusion coefficients of $D<10^{-8} \mathrm{~cm}^{2} \mathrm{~s}^{-1}$ which cannot explain the experimental observation. Likewise, for perfectly ordered and off-stoichiometric crystals - generated by removing few ions from the simulation cell - we obtained negligible $D_{\mathrm{Li}+}$ and $D_{\mathrm{Na}}$ values. These results indicate that the likely cause for the large ionic diffusion observed in our experiments is not the creation of intrinsic defects induced by temperature. In fact, the formation energy of $\mathrm{Li}^{+}$and $\mathrm{Na}^{+}$Frenkel defects (i.e., simultaneous generation of one vacancy and one interstitial in the crystal) that we calculated for $\mathrm{LiMn}\left(\mathrm{HCO}_{2}\right)_{3}$ and $\mathrm{NaMn}\left(\mathrm{HCO}_{2}\right)_{3}$, $E_{\text {Frenkel }} \sim 3 \mathrm{eV}$, is noticeably larger than the defect energies estimated for intrinsic superionic materials (e.g., $E_{\text {Frenkel }} \sim 2 \mathrm{eV}$ in $\mathrm{CaF}_{2}^{28}$ ). The physical origin of this result is the attractive interactions between the alkali metal ions and highly distorted $\mathrm{O}_{6}$ octahedra that surround them (Figs. $4 \mathrm{c}$ and d), which severely restrict the $\mathrm{Li}^{+}$and $\mathrm{Na}^{+}$mobility. Nevertheless, by considering a small concentration of $\mathrm{Li}^{+}$and $\mathrm{Na}^{+}$Frenkel defects $(\sim 1 \%)$ in our simulations, we were able to reproduce significant ionic diffusion for $\operatorname{LiMn}\left(\mathrm{HCO}_{2}\right)_{3}$ and $\mathrm{NaMn}\left(\mathrm{HCO}_{2}\right)_{3}$ (Figure 4a and b), namely, $D_{\mathrm{Li}}=6.3 \cdot 10^{-7}$ and $D_{\mathrm{Na}}=2.5 \cdot 10^{-6} \mathrm{~cm}^{2} \mathrm{~s}^{-1}$ at $T=900 \mathrm{~K}$. The agreement between the simulated $D$ 's and the corresponding experimental values is far from perfect. However, this quantitative disagreement can be regarded as normal since the origin of the observed ionic transport appears to be extrinsic defects, which are generated during the materials synthesis 
and cannot be quantified straightforwardly. On the other hand, at the qualitative level, our theoretical results are fully consistent with our experimental results since the diffusion coefficient of sodium ions is noticeably larger than that of lithium ions.
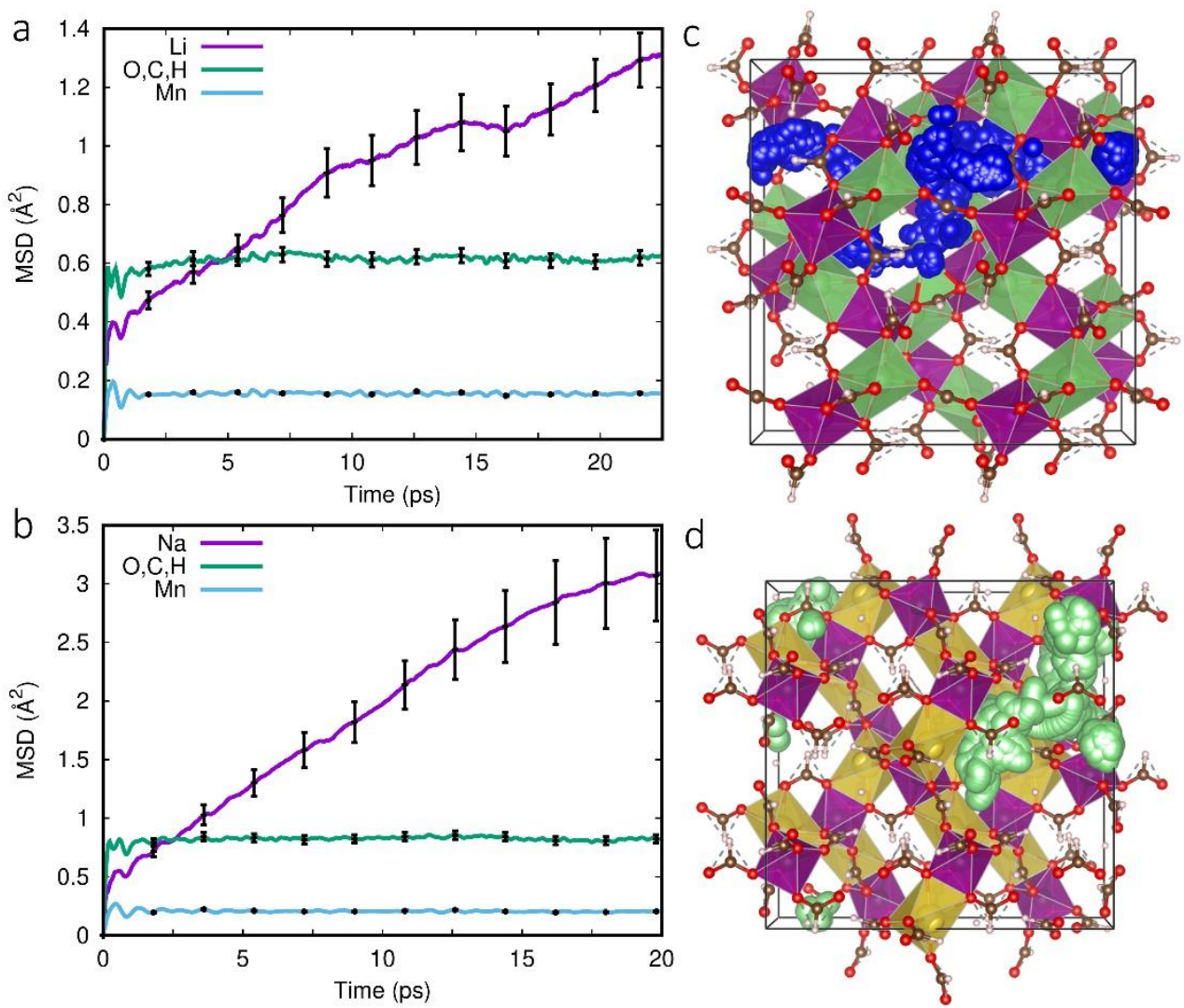

Figure 4. First-principles calculation of the ionic transport properties of bulk $\operatorname{LiMn}\left(\mathrm{HCO}_{2}\right)_{3}$ and $\mathrm{NaMn}\left(\mathrm{HCO}_{2}\right)_{3}$. Estimation of the ionic mean-squared displacements (MSD) for bulk (a) $\mathrm{LiMn}\left(\mathrm{HCO}_{2}\right)_{3}$ and (b) $\mathrm{NaMn}\left(\mathrm{HCO}_{2}\right)_{3}$ at $T=900 \mathrm{~K}$. The AIMD trajectory of (c) a mobile Li ion in bulk $\mathrm{LiMn}\left(\mathrm{HCO}_{2}\right)_{3}$ and (d) a mobile $\mathrm{Na}$ ion in bulk $\mathrm{NaMn}\left(\mathrm{HCO}_{2}\right)_{3}$. $\mathrm{Li}, \mathrm{Na}, \mathrm{O}, \mathrm{H}$ and $\mathrm{C}$ ions are represented with dark green, gold, red, pink, and brown spheres, respectively. The mobile $\mathrm{Li}$ and $\mathrm{Na}$ ions are represented with blue and light green spheres, respectively.

By analyzing the AIMD trajectories of mobile ions (Figure 4c and $\mathbf{d}$ ), we were able to identify a characteristic ionic diffusion mechanism for heterometallic formate frameworks that resembles that of a metallic sphere in a "pinball" machine. In particular, the diffusion of the alkali metal ions ("metallic balls") appears to be supported by the librational motion of the formate anions ("flippers"), which are light and flexible. Interestingly, we found that the 
interactions of formate anions (“flippers"), which are light and flexible. Interestingly, we found that the interactions of formate anions with mobile $\mathrm{Na}$ ions are more attractive than with $\mathrm{Li}$ ions. Despite of its larger size, the average distance between the mobile sodium ion and the formate anion, $\left\langle d_{\mathrm{Na}-\mathrm{FA}}\right\rangle=1.90 \AA$, is smaller than for the mobile lithium ion, $\left\langle d_{\mathrm{Li}-\mathrm{FA}}\right\rangle=1.98$ $\AA$. We believe that the identified disparity in the chemical forces acting between "metallic balls" and "flippers" can explain the origin of the enhanced ionic diffusion observed for Nabased formate frameworks. It is worth noting that in terms of the relative available interstitial volume, both $\mathrm{LiMn}\left(\mathrm{HCO}_{2}\right)_{3}$ and $\mathrm{NaMn}\left(\mathrm{HCO}_{2}\right)_{3}$ compounds are pretty similar.

Reversible $\mathrm{Na}^{+}$storage behavior. Preliminary electrochemical cycling at a $0.05 \mathrm{C}$ rate revealed reversible $\mathrm{Na}^{+}$storage in $\mathrm{Na}_{2} \mathrm{Co}\left(\mathrm{HCO}_{2}\right)_{4}\left(\right.$ Figure 5a) and $\mathrm{NaMn}\left(\mathrm{HCO}_{2}\right)_{3}($ Figure 5b) at an average voltage of 2.5-3 V. For the cycling of both Na-ions accompanying $\mathrm{Co}^{2+} / \mathrm{Co}^{3+}$ and $\mathrm{Co}^{3+} / \mathrm{Co}^{4+}$ redox, the theoretical capacity of $\mathrm{Na}_{2} \mathrm{Co}\left(\mathrm{HCO}_{2}\right)_{4}$ is $188 \mathrm{mAh} \mathrm{g}^{-1}$ which is very close to that of high capacity layered transition metal oxides. ${ }^{2}$ In comparison, $\mathrm{NaMn}\left(\mathrm{HCO}_{2}\right)_{3}$ can deliver a maximum of $126 \mathrm{mAh} \mathrm{g}{ }^{-1}$, corresponding to the $\mathrm{Mn}^{2+} / \mathrm{Mn}^{3+}$ redox. Polyanionic systems like $\mathrm{Na}_{3} \mathrm{~V}_{2}\left(\mathrm{PO}_{4}\right)_{3}$ and $\mathrm{NaFePO}_{4}$ possess comparable specific capacity. ${ }^{2}$ Experimentally, $\mathrm{Na}_{2} \mathrm{Co}\left(\mathrm{HCO}_{2}\right)_{4}$ delivers a reversible capacity of $60 \mathrm{mAh} \mathrm{g}{ }^{-1}$ corresponding to the cycling of only $0.6 \mathrm{Na}^{+}$. Even though $\mathrm{NaMn}\left(\mathrm{HCO}_{2}\right)_{3}$ delivers a higher initial reversible capacity of $\sim 100 \mathrm{mAh} \mathrm{g}^{-1}$, electrolyte decomposition - most likely catalyzed by the transition metal - is apparent at high charging voltages during the first few cycles. In comparison, $\mathrm{LiMn}\left(\mathrm{HCO}_{2}\right)_{3}$ displays (Figure S6) a low capacity of $30 \mathrm{~mA} \mathrm{~h} \mathrm{~g}^{-1}$ owing to its poor Li-ionic conductivity. Figure $\mathbf{5 c}$ and $\mathbf{d}$ show the differential capacity plots corresponding to the galvanostatic data shown in Figure 5a and b, respectively. While reproducible profile in both plots confirms the reversible nature of the involved electrochemical processes, the large gap between the oxidation and reduction peaks highlights the large voltage polarization in both systems. For $\mathrm{Na}_{2} \mathrm{Co}\left(\mathrm{HCO}_{2}\right)_{4}$, the oxidation peak at $3.9 \mathrm{~V}$ (first cycle) moves to $3.6 \mathrm{~V}$ and 
stabilizes after the second cycle indicating an irreversible structural adjustment during the first cycle. Whereas, $\mathrm{NaMn}\left(\mathrm{HCO}_{2}\right)_{3}$ peaks maintain their position throughout, but the peak current diminishes with cycling in accordance with capacity fading with increasing cycle number. Figure 5e and $\mathbf{f}$ present the specific capacity and the Coulombic efficiency as a function of cycle number for $\mathrm{Na}_{2} \mathrm{Co}\left(\mathrm{HCO}_{2}\right)_{4}$ and $\mathrm{NaMn}\left(\mathrm{HCO}_{2}\right)_{3}$, respectively. Both show a significant discrepancy between the charge and the discharge capacities, leading to Coulombic efficiencies of $\sim 90 \%$. $\mathrm{Na}_{2} \mathrm{Co}\left(\mathrm{HCO}_{2}\right)_{4}$ shows slightly better cyclability and Coulombic efficiency compared to $\mathrm{NaMn}\left(\mathrm{HCO}_{2}\right)_{3}$. Despite the incorporation of a significant amount $(25 \%)$ of conductive carbon in the electrode mixture, large voltage polarization is common to all systems, which hinder attainment of full capacity and good cycling stability. While the ionic conductivity is relatively higher than most inorganic polyanion cathode hosts like NASICON Na $3 \mathrm{~V}_{2}\left(\mathrm{PO}_{4}\right)_{3}{ }^{29}$ or cubic $\mathrm{Na}_{3} \mathrm{TiP}_{3} \mathrm{O}_{9} \mathrm{~N}^{30}$ (both $\sim 10^{-7} \mathrm{~S} \mathrm{~cm}^{-1}$ ), it is likely that the performance limitation stems from the low electronic conductivity and relatively large particle size of the formate materials. In this regard, the development of uniform nanostructured formates and conductive composite formation by conductive polymer coating or graphene wrapping - both of which can be achieved in situ by modifying the synthesis condition - are likely solutions. Nevertheless, galvanostatic cycling of the as obtained microcrystalline formates clearly demonstrate reversible $\mathrm{Na}^{+}$storage is feasible in the formate frameworks, which has not been reported in literature so far.

\section{CONCLUSION}

In summary, we have developed a microwave synthesis methodology for the rapid and versatile synthesis of heterometallic formate frameworks. The obtained phase pure polycrystalline materials are thermally stable up to $200-250^{\circ} \mathrm{C}$ and display intriguing $\mathrm{Na}^{+} / \mathrm{Li}^{+}$conduction behavior. Particularly impressive is the four orders of magnitude higher $\mathrm{Na}^{+}$conductivity of $\mathrm{NaMn}\left(\mathrm{HCO}_{2}\right)_{3}$ compared to the $\mathrm{Li}^{+}$conductivity of $\mathrm{LiMn}\left(\mathrm{HCO}_{2}\right)_{3}$ despite both having an 
identical crystal structure. Prevalence of interstitial defects in the as-synthesized compounds and librational motion of the formate anions which interact strongly with the $\mathrm{Na}$ ions appears to facilitate the diffusion of $\mathrm{Na}^{+}$compared to $\mathrm{Li}^{+}$, as revealed by theoretical calculations. The capability of the Na-analogues to reversibly store $\mathrm{Na}^{+}$is confirmed by preliminary electrochemical measurements.
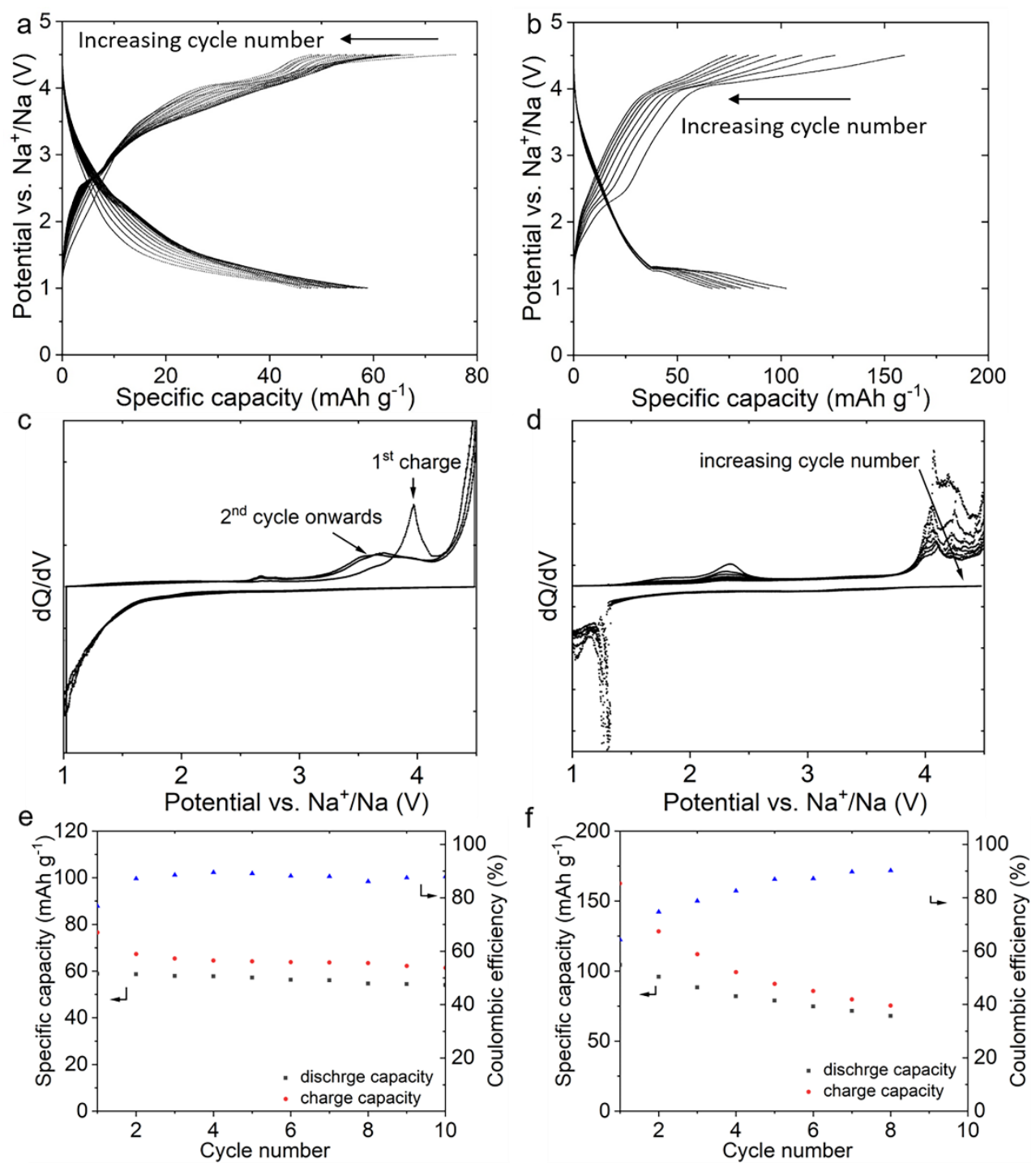

Figure 5. Galvanostatic charge-discharge profiles of (a) $\mathrm{Na}_{2} \mathrm{Co}\left(\mathrm{HCO}_{2}\right)_{4}$ and (b) $\mathrm{NaMn}\left(\mathrm{HCO}_{2}\right)_{3}$ against a metallic $\mathrm{Na}$ anode at a $0.05 \mathrm{C}$ rate with $1 \mathrm{M} \mathrm{NaClO}_{4}$ in $\mathrm{EC} / \mathrm{PC} / \mathrm{FEC}$ as the electrolyte. (c) and (d) present the corresponding differential capacity plots for $\mathrm{Na}_{2} \mathrm{Co}\left(\mathrm{HCO}_{2}\right)_{4}$ $\mathrm{NaMn}\left(\mathrm{HCO}_{2}\right)_{3}$, respectively. The cyclability data and the Coulombic efficiency evolution of (e) $\mathrm{Na}_{2} \mathrm{Co}\left(\mathrm{HCO}_{2}\right)_{4}$ and (f) $\mathrm{NaMn}\left(\mathrm{HCO}_{2}\right)_{3}$. 


\section{EXPERIMENTAL METHODS}

Synthesis. For the synthesis of $\mathrm{Na}_{2} \mathrm{Co}\left(\mathrm{HCO}_{2}\right)_{4}$ and $\mathrm{NaMn}\left(\mathrm{HCO}_{2}\right)_{3}$ a mixture of $1 \mathrm{mmol}$ $\mathrm{Co}\left(\mathrm{NO}_{3}\right)_{2} \cdot 6 \mathrm{H}_{2} \mathrm{O}$ (Acros Organics, $99 \%$ purity) or $1 \mathrm{mmol} \mathrm{Mn}\left(\mathrm{NO}_{3}\right)_{2} \cdot 4 \mathrm{H}_{2} \mathrm{O}$ (Sigma Aldrich, $\geq$ $97.0 \%$ purity) and $6 \mathrm{mmol} \mathrm{HCO}_{2} \mathrm{Na}$ (Sigma Aldrich, $\geq 99.0 \%$ purity) was dissolved in $10 \mathrm{~mL}$ of N,N-Dimethylformamide (DMF, Fisher Chemical, extra pure) in a $35 \mathrm{~mL}$ pressure vessel (Pyrex, CEM). For $\mathrm{LiCo}\left(\mathrm{HCO}_{2}\right)_{3}$ and $\mathrm{LiMn}\left(\mathrm{HCO}_{2}\right)_{3}, \mathrm{HCO}_{2} \mathrm{Li} \cdot \mathrm{H}_{2} \mathrm{O}$ was used instead of $\mathrm{HCO}_{2} \mathrm{Na}$. After thoroughly stirring for at least an hour, the dispersion turned turbid. The vessel was placed inside a microwave synthesizer (CEM, Explorer 12 SP Hybrid) and heated up to $160 \mathrm{C}^{\circ}$ with a maximum power of $160 \mathrm{~W}$. The mixture was kept at this temperature for $30 \mathrm{~min}$. Each product was rinsed three times with ethanol (technical grade), using a centrifuge (Hettich, 14 model universal 320) and redispersed by vortex followed by drying under vacuum overnight. After drying the $\mathrm{Na}_{2} \mathrm{Co}\left(\mathrm{HCO}_{2}\right)_{4}$ powder had a copper rose color and $\mathrm{NaMn}\left(\mathrm{HCO}_{2}\right)_{3}$ as well as $\mathrm{LiMn}\left(\mathrm{HCO}_{2}\right)_{3}$ had a cream beige color, while $\mathrm{LiCo}\left(\mathrm{HCO}_{2}\right)_{3}$ was pink. The same synthesis was performed to obtain $\mathrm{NaCo}\left(\mathrm{HCO}_{2}\right)_{3}$, but the product was impure.

Physicochemical characterization. The materials were characterized with X-ray diffraction (XRD), scanning electron microscopy (SEM), elemental microanalysis, attenuated total reflection infrared spectroscopy (ATR-IR) and thermal gravimetric analysis (TGA). XRD was measured on a PANalytical XpertPro equipped with a X'Celerator RTMS detector and a $\mathrm{Cu}$ $\mathrm{K}_{\alpha} \mathrm{X}$-ray tube $(\lambda=1.5405 \AA)$ in the range from $5^{\circ}$ to $80^{\circ}(2 \theta)$ with a step size of $0.033^{\circ}$. SEM was performed on ZEISS Leo 1530 FEG equipped with an energy dispersive X-ray spectroscopy (EDX) attachment. For TGA, a TA Instruments Q500 was used, with the samples heated from $30{ }^{\circ} \mathrm{C}$ to $900{ }^{\circ} \mathrm{C}$ under nitrogen atmosphere at a heating rate of $10{ }^{\circ} \mathrm{C} \mathrm{min}^{-1}$. Infrared spectroscopic analysis was performed on Bruker Optics Alpha system with a built-in diamond ATR.

Ionic conductivity and electrochemical studies. For temperature dependent ionic conductivity measurements, pellets were pressed at $500 \mathrm{MPa}$ with a uniaxial press (MTI corporation). The pellets were sintered at $150^{\circ} \mathrm{C}$ overnight and sandwiched between two stainless steel rods under Ar atmosphere. Contact problems were eliminated by applying a conductive silver paste on both sides of the pellets and the stainless steel rods. Bulk resistance measurements were performed by two probe ac impedance spectroscopy (SP-150, BioLogic) in the $400 \mathrm{kHz}-100 \mathrm{mHz}$ range with perturbation of $200 \mathrm{mV}$. Impedance data were recorded in the $50^{\circ} \mathrm{C}-170^{\circ} \mathrm{C}$ window. The data were fitted with equivalent circuit models shown in Figure S5 using the EC-lab Z-fit software to extract the ionic conductivities. The activation 
energy for $\mathrm{Na}^{+} / \mathrm{Li}^{+}$diffusion was obtained by linear fitting of the bulk ionic conductivity values at different temperatures by applying Arrhenius equation with a temperature dependent preexponential factor: $\sigma \mathrm{T}=\sigma_{0} \exp \left(-\mathrm{E}_{\mathrm{A}} / \mathrm{k}_{\mathrm{b}} \mathrm{T}\right) . \sigma$ is the temperature dependent bulk ionic conductivity, $\sigma_{0}$ is the ionic conductivity at absolute zero temperature, $\mathrm{E}_{\mathrm{A}}$ is the activation energy for ion migration, $\mathrm{k}_{\mathrm{b}}$ is the Boltzmann constant and $\mathrm{T}$ is the temperature in kelvin.

For electrode fabrication, the formates were mixed with conductive carbon black Super P (Timcal) and polyvinylidene fluoride or PVDF (Sigma Aldrich, $\mathrm{M}_{\mathrm{W}}$ 534.000) in 70:25:5 ratio. A small amount of N-methly-2-pyrrolidone (Sigma Aldrich, 99\% purity) was added to the mixture to obtain a viscus slurry that was spread with a doctor blade on an aluminum foil (MTI). The film was first dried under vacuum in a desiccator and then placed in a vacuum oven to dry overnight at $100{ }^{\circ} \mathrm{C}$. Circular electrodes $(\varnothing=11 \mathrm{~mm})$ were punched out of the film. Swagelok-type cells were assembled with two pieces of glass fiber separator (GF/A) placed in between the electrodes, where the anode was Na metal. $100 \mu \mathrm{l}$ of $1 \mathrm{M} \mathrm{NaClO}_{4}$ in $\mathrm{EC} / \mathrm{PC} / \mathrm{FEC}$ (49:49:2 by volume) and 1M LiPF6 in EC/DMC (1:1 by volume) was used as electrolytes.

Theoretical calculations. Ab initio molecular dynamics (AIMD) simulations based on DFT were performed in the canonical $(N, V, T)$ ensemble (constant number of particles, volume, and temperature). The temperature in the AIMD simulations was kept fluctuating around a setpoint value by using Nose-Hoover thermostats. Large simulation boxes containing 448 atoms were employed and periodic boundary conditions were applied along the three Cartesian directions. Off-stoichiometric systems were generated by removing one lithium or sodium atom from the stoichiometric simulation cell. Newton's equations of motion were integrated by using the Verlet algorithm with a timestep of $10^{-3} \mathrm{ps}$. $\Gamma$-point sampling for Brillouin zone integration was employed in all the AIMD simulations. Our calculations comprised total simulation times of about 50 picoseconds (ps) and for each compound we performed a total of 7 AIMD simulations considering different temperatures and compositions.

To quantify the transport properties of the selected materials we computed the corresponding mean-squared displacement (MSD), $\Delta r^{2}(t)$, and diffusion coefficient, $D$, for all the involved ionic species. The ionic mean-squared displacements were calculated according to the definition: $\left\langle\Delta r_{i}^{2}(t)\right\rangle=\left\langle\left|r_{i}\left(t+t_{o}\right)-r_{i}\left(t_{0}\right)\right|^{2}\right\rangle$, where $r_{i}(t)$ is the position of the migrating ion labelled as $i$ at time $t, t_{0}$ an arbitrary time origin, and $\langle\ldots\rangle$ denotes average over atoms and time origins. By averaging over different time origins, we accumulated enough statistics to reduce significantly the MSD numerical fluctuations at long times, thus obtaining accurate $D$ 
values. ${ }^{27}$ Meanwhile, the ionic diffusion coefficients were estimated with the well-known formula: $D=\lim _{t \rightarrow \infty} \frac{\left\langle\left|r_{i}\left(t+t_{o}\right)-r_{i}\left(t_{o}\right)\right|^{2}\right\rangle}{6 t}$.

\section{ASSOCIATED CONTENT}

\section{Supporting Information}

Theoretical calculation details, X-ray data of $\mathrm{NaCo}\left(\mathrm{HCO}_{2}\right)_{3}$ synthesis products, FTIR data, thermal analysis results, carbon analysis result, SEM-EDX data of $\mathrm{Na}_{2} \mathrm{Co}\left(\mathrm{HCO}_{2}\right)_{4}$ and $\mathrm{NaCo}\left(\mathrm{HCO}_{2}\right)_{3}$, equivalent circuits used for impedance data fitting, parameters obtained from impedance data fitting, bulk ionic conductivities at room temperature, and reversible $\mathrm{Li}+$ storage performance of $\mathrm{LiMn}\left(\mathrm{HCO}_{2}\right)_{3}$.

\section{AUTHOR CONTRIBUTIONS}

D.K. conceived the idea and designed the experimental work with help from A.P. A.P. carried out all the experimental studies and data analysis and C.C. performed the computational work. D.K. wrote the manuscript with help from all authors.

\section{ACKNOWLEDGEMENTS}

D.K. acknowledges the Swiss National Science Foundation (SNSF) for the financial support for this work through their Ambizione grant. D.K. also acknowledges the UNSW for the support through the start-up grant.

\section{REFERENCES}

(1) Vaalma, C.; Buchholz, D.; Weil, M.; Passerini, S. A Cost and Resource Analysis of Sodium-Ion Batteries. Nat. Rev. Mater. 2018, 3, 18013. https://doi.org/10.1038/natrevmats.2018.13.

(2) Hwang, J.-Y.; Myung, S.-T.; Sun, Y.-K. Sodium-Ion Batteries: Present and Future. Chem. Soc. Rev. 2017, 46, 3529-3614. https://doi.org/10.1039/C6CS00776G.

(3) Yabuuchi, N.; Kubota, K.; Dahbi, M.; Komaba, S. Research Development on SodiumIon Batteries. Chem. Rev. 2014, 114, 11636-11682. https://doi.org/10.1021/cr500192f.

(4) Kundu, D.; Talaie, E.; Duffort, V.; Nazar, L. F. The Emerging Chemistry of Sodium Ion Batteries for Electrochemical Energy Storage. Angew. Chem. Int. Ed. 2015, 54, 3431-3448. https://doi.org/10.1002/anie.201410376.

(5) Cheng, N.; Ren, L.; Xu, X.; Du, Y.; Dou, S. X. Application of Organic-Inorganic Hybrids in Lithium Batteries. Materials Today Physics 2020, 100289. https://doi.org/10.1016/j.mtphys.2020.100289.

(6) Morozan, A.; Jaouen, F. Metal Organic Frameworks for Electrochemical Applications. Energy Environ. Sci. 2012, 5, 9269. https://doi.org/10.1039/c2ee22989g. 
(7) Song, Z.; Zhou, H. Towards Sustainable and Versatile Energy Storage Devices: An Overview of Organic Electrode Materials. Energy Environ. Sci. 2013, 6, 2280. https://doi.org/10.1039/c3ee40709h.

(8) Shahul Hameed, A.; Nagarathinam, M.; Schreyer, M.; Reddy, M. V.; Chowdari, B. V. R.; Vittal, J. J. A Layered Oxalatophosphate Framework as a Cathode Material for LiIon Batteries. J. Mater. Chem. A 2013, 1, 5721. https://doi.org/10.1039/c3ta10464h.

(9) Fernández de Luis, R.; Ponrouch, A.; Rosa Palacín, M.; Karmele Urtiaga, M.; Arriortua, M. I. Electrochemical Behavior of $\left[\{\mathrm{Mn}(\mathrm{Bpy})\}\left(\mathrm{VO}_{3}\right)_{2}\right] \approx\left(\mathrm{H}_{2} \mathrm{O}\right)_{1.24}$ and $\left[\left\{\mathrm{Mn}(\mathrm{Bpy})_{0.5}\right\}\left(\mathrm{VO}_{3}\right)_{2}\right] \approx\left(\mathrm{H}_{2} \mathrm{O}\right)_{0.62}$ Inorganic-Organic Brannerites in Lithium and Sodium Cells. Journal of Solid State Chemistry 2014, 212, 92-98.

https://doi.org/10.1016/j.jssc.2014.01.013.

(10) Lin, Y.; Zhang, Q.; Zhao, C.; Li, H.; Kong, C.; Shen, C.; Chen, L. An Exceptionally Stable Functionalized Metal-Organic Framework for Lithium Storage. Chem. Commun. 2015, 51, 697-699. https://doi.org/10.1039/C4CC07149B.

(11) Schmidt, S.; Sheptyakov, D.; Jumas, J.-C.; Medarde, M.; Benedek, P.; Novák, P.; Sallard, S.; Villevieille, C. Lithium Iron Methylenediphosphonate: A Model Material for New Organic-Inorganic Hybrid Positive Electrode Materials for Li Ion Batteries. Chem. Mater. 2015, 27, 7889-7895. https://doi.org/10.1021/acs.chemmater.5b02595.

(12) Zhao, R.; Liang, Z.; Zou, R.; Xu, Q. Metal-Organic Frameworks for Batteries. Joule 2018, 2, 2235-2259. https://doi.org/10.1016/j.joule.2018.09.019.

(13) Wang, L.; Han, Y.; Feng, X.; Zhou, J.; Qi, P.; Wang, B. Metal-Organic Frameworks for Energy Storage: Batteries and Supercapacitors. Coord. Chem. Rev. 2016, 307, 361381. https://doi.org/10.1016/j.ccr.2015.09.002.

(14) Li, X.; Cheng, F.; Zhang, S.; Chen, J. Shape-Controlled Synthesis and Lithium-Storage Study of Metal-Organic Frameworks $\mathrm{Zn}_{4} \mathrm{O}(1,3,5 \text {-Benzenetribenzoate })_{2}$. J. Power Sources 2006, 160 (1), 542-547. https://doi.org/10.1016/j.jpowsour.2006.01.015.

(15) Fateeva, A.; Horcajada, P.; Devic, T.; Serre, C.; Marrot, J.; Grenèche, J.-M.; Morcrette, M.; Tarascon, J.-M.; Maurin, G.; Férey, G. Synthesis, Structure, Characterization, and Redox Properties of the Porous MIL-68(Fe) Solid. Eur. J. Inorg. Chem. 2010, 2010, 3789-3794. https://doi.org/10.1002/ejic.201000486.

(16) Zhang, Z.; Yoshikawa, H.; Awaga, K. Monitoring the Solid-State Electrochemistry of $\mathrm{Cu}(2,7-\mathrm{AQDC})(\mathrm{AQDC}=$ Anthraquinone Dicarboxylate $)$ in a Lithium Battery: Coexistence of Metal and Ligand Redox Activities in a Metal-Organic Framework. $J$. Am. Chem. Soc. 2014, 136, 16112-16115. https://doi.org/10.1021/ja508197w.

(17) Férey, G.; Millange, F.; Morcrette, M.; Serre, C.; Doublet, M.-L.; Grenèche, J.-M.; Tarascon, J.-M. Mixed-Valence Li/Fe-Based Metal-Organic Frameworks with Both Reversible Redox and Sorption Properties. Angew. Chem. Int. Ed. 2007, 46, 32593263. https://doi.org/10.1002/anie.200605163.

(18) Férey, G.; Millange, F.; Morcrette, M.; Serre, C.; Doublet, M.-L.; Grenèche, J.-M.; Tarascon, J.-M. Mixed-Valence Li/Fe-Based Metal-Organic Frameworks with Both Reversible Redox and Sorption Properties. Angew. Chem. Int. Ed. 2007, 46, 32593263. https://doi.org/10.1002/anie.200605163.

(19) Pramanik, M.; Tsujimoto, Y.; Malgras, V.; Dou, S. X.; Kim, J. H.; Yamauchi, Y. Mesoporous Iron Phosphonate Electrodes with Crystalline Frameworks for LithiumIon Batteries. Chem. Mater. 2015, 27, 1082-1089. https://doi.org/10.1021/cm5044045. 
(20) Xia, S.; Li, F.; Li, X.; Cheng, F.; Sun, C.; Liu, J.-J.; Guo, H. An Inorganic-Organic Hybrid Supramolecular Framework as a High-Performance Anode for Lithium-Ion Batteries. Dalton Trans. 2018, 47, 5166-5170. https://doi.org/10.1039/C8DT00335A.

(21) Song, Y.; Yu, L.; Gao, Y.; Shi, C.; Cheng, M.; Wang, X.; Liu, H.-J.; Liu, Q. OneDimensional Zinc-Based Coordination Polymer as a Higher Capacity Anode Material for Lithium Ion Batteries. Inorg. Chem. 2017, 56, 11603-11609. https://doi.org/10.1021/acs.inorgchem.7b01441.

(22) Chen, T.; Liu, X.; Niu, L.; Gong, Y.; Li, C.; Xu, S.; Pan, L. Recent Progress on MetalOrganic Framework-Derived Materials for Sodium-Ion Battery Anodes. Inorg. Chem. Front. 2020, 7, 567-582. https://doi.org/10.1039/C9QI01268K.

(23) Zhao, J.-P.; Han, S.-D.; Zhao, R.; Yang, Q.; Chang, Z.; Bu, X.-H. Tuning the Structure and Magnetism of Heterometallic Sodium(1+)-Cobalt(2+) Formate Coordination Polymers by Varying the Metal Ratio and Solvents. Inorg. Chem. 2013, 52, 28622869. https://doi.org/10.1021/ic301936k.

(24) Eikeland, E.; Lock, N.; Filsø, M.; Stingaciu, M.; Shen, Y.; Overgaard, J.; Iversen, B. B. Alkali Metal Ion Templated Transition Metal Formate Framework Materials: Synthesis, Crystal Structures, Ion Migration, and Magnetism. Inorg. Chem. 2014, 53, 10178-10188. https://doi.org/10.1021/ic501152j.

(25) Aston, J. C.; Saines, P. J. Transition-Metal Dependent Cation Disorder in the Chiral Cubic $A B\left(\mathrm{HCO}_{2}\right)_{3}$ Metal-Organic Frameworks $(A=\mathrm{Li}$ or Na, $B=\mathrm{Mn}$ or $\mathrm{Co}$ ):

Transition-Metal Dependent Cation Disorder in the Chiral Cubic $A B\left(\mathrm{HCO}_{2}\right)_{3}$ MetalOrganic Frameworks ( $A=\mathrm{Li}$ or Na, $B=\mathrm{Mn}$ or Co). Z. Anorg. Allg. Chem. 2017, 643, 287-293. https://doi.org/10.1002/zaac.201600350.

(26) Deng, Z.; Mo, Y.; Ong, S. P. Computational Studies of Solid-State Alkali Conduction in Rechargeable Alkali-Ion Batteries. NPG Asia Mater 2016, 8, e254-e254. https://doi.org/10.1038/am.2016.7.

(27) Sagotra, A. K.; Chu, D.; Cazorla, C. Influence of Lattice Dynamics on Lithium-Ion Conductivity: A First-Principles Study. Phys. Rev. Mater. 2019, 3, 035405. https://doi.org/10.1103/PhysRevMaterials.3.035405.

(28) Cazorla, C.; Errandonea, D. Giant Mechanocaloric Effects in Fluorite-Structured Superionic Materials. Nano Lett. 2016, 16 (5), 3124-3129. https://doi.org/10.1021/acs.nanolett.6b00422.

(29) Lalère, F.; Leriche, J. B.; Courty, M.; Boulineau, S.; Viallet, V.; Masquelier, C.; Seznec, V. An All-Solid State NASICON Sodium Battery Operating at $200{ }^{\circ} \mathrm{C}$. Journal of Power Sources 2014, 247, 975-980. https://doi.org/10.1016/j.jpowsour.2013.09.051.

(30) Liu, J.; Chang, D.; Whitfield, P.; Janssen, Y.; Yu, X.; Zhou, Y.; Bai, J.; Ko, J.; Nam, K.-W.; Wu, L.; Zhu, Y.; Feygenson, M.; Amatucci, G.; Van der Ven, A.; Yang, X.-Q.; Khalifah, P. Ionic Conduction in Cubic $\mathrm{Na}_{3} \mathrm{TiP}_{3} \mathrm{O}_{9} \mathrm{~N}$, a Secondary Na-Ion Battery Cathode with Extremely Low Volume Change. Chem. Mater. 2014, 26, 3295-3305. https://doi.org/10.1021/cm5011218. 
TOC Graphic (For Table of Contents Only)

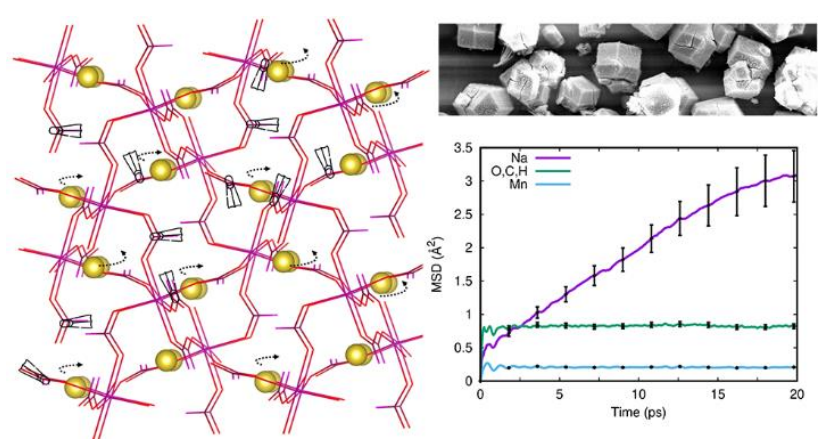

